Jurnal Qua Teknika, Vol.6 No.2 September 2016

p ISSN: 2088 2424; e ISSN: 2527 3892

UNISBA Blitar, Http://qua.unisbablitar.ejournal.web.id

Budi Artono, 2016. Telepon Selular Sebagai Pengendali Perangkat Elektronik Berbasis Mikrokontrol AT

89C51. Jurnal Qua Teknika, (2016), 6(2): 29 45

\title{
TELEPON SELULAR SEBAGAI PENGENDALI PERANGKAT ELEKTRONIK BERBASIS MIKROKONTROL AT 89C51
}

\author{
Budi Artono \\ Institut Teknologi Nasional \\ Jl. Bendungan Sigura-Gura No. 2, Lowokwaru, Malang
}

\begin{abstract}
Abstrak
Untuk memanfaatkan sinyal DTMF (Dual Tone Multiple Frequency) telepon selular serta kemampuan mikrokontroler yang digunakan untuk mengendalikan perangkat elektronik agar nantinya diperoleh suatu kemudahan dalam pengendaliannya yang sudah tidak dibatasi dimensi jarak, ruang dan waktu. Pengendalian ini berbasis mikrokontroler agar nantinya dapat mengendalikan beberapa beban Peralatan Elektronik hanya dengan satu kontrol utama sehingga efisiensi dapat tercapai.
\end{abstract}

Kata Kunci: telepon seluler, kendali, mikrokontroler

\section{PENDAHULUAN}

Sejalan dengan perkembangan peradaban manusia dewasa ini ada suatu perubahan secara signifikan diberbagai aspek kehidupan. Perubahan ini berimbas juga pada perkembangan teknologi elektronika khususnya telepon selular. Teknologi telepon selular, tampaknya semakin berkembang dengan pesat. Rasanya setiap detik, teknologi ini melesat menuju ke sebuah fungsi generasi masa depan yang sebelumnya hanyalah merupakan suatu imajinasi dan angan-angan futuristik dalam dunia hiburan. Perkembangan sebuah sistem Telepon Selular (Ponsel) atau Hand Phone (HP) ini telah mengalami evolusi yang panjang, sebelum melesat perkembangannya seperti sekarang ini. Selular tidak hanya sarana komunikasi suara seperti pada awal teknologi selular ini ditemukan, akan tetapi saat ini telah menjadi sebuah piranti canggih, sebagai media komunikasi yang mempunyai fungsi yang sangat luas karena berkembangnya teknologi nirkabel dan teknologi transmisi data. Perkembangan jaringan telepon selular tidak terlepas dari berkembangnya teknologi jaringan nirkabel sehingga di dalam waktu selanjutnya tidak mustahil bahwa selular akan menjadi suatu workstation atau client computer yang terdedikasi pada sebuah server jaringan nirkabel yang menyediakan layanan client server. Layanan telepon selular telah menjadi kebutuhan penting, yang dalam tahun mendatang tidak mustahil akan menggeser layanan telepon tradisional. Dengan kemampuannya yang semakin berkembang, ternyata media telepon selular mempunyai ruang gerak perkembangan teknologi yang tidak terbendung lagi. Melihat realita perkembangan teknologi selular seperti yang dikemukakan diatas, maka penulis tertarik untuk mengaplikasikan telepon selular sebagai pengendali peralatan elektronika lainnya. Sehingga penulis ingin membahas telepon selular sebagai pengendali perangkat elektronik berbasis mikrokontrol AT 89C51.

Untuk memanfaatkan sinyal DTMF (Dual Tone Multiple Frequency) telepon selular serta kemampuan mikrokontroler yang digunakan untuk mengendalikan perangkat elektronik agar nantinya diperoleh suatu kemudahan dalam pengendaliannya yang sudah tidak dibatasi dimensi jarak, ruang dan waktu. Pengendalian ini berbasis mikrokontroler agar nantinya dapat mengendalikan beberapa beban Peralatan Elektronik hanya dengan satu kontrol utama sehingga efisiensi dapat tercapai. 


\section{PERANCANGAN SISTEM}

\subsection{Gambaran Umum Sistem}

Perancangan perangkat keras yang dibuat dalam Penelitian ini terdiri dari beberapa bagian dimana diagram blok dari perangkat keras tersebut adalah seperti ditunjukkan dalam gambar 3.1 berikut.

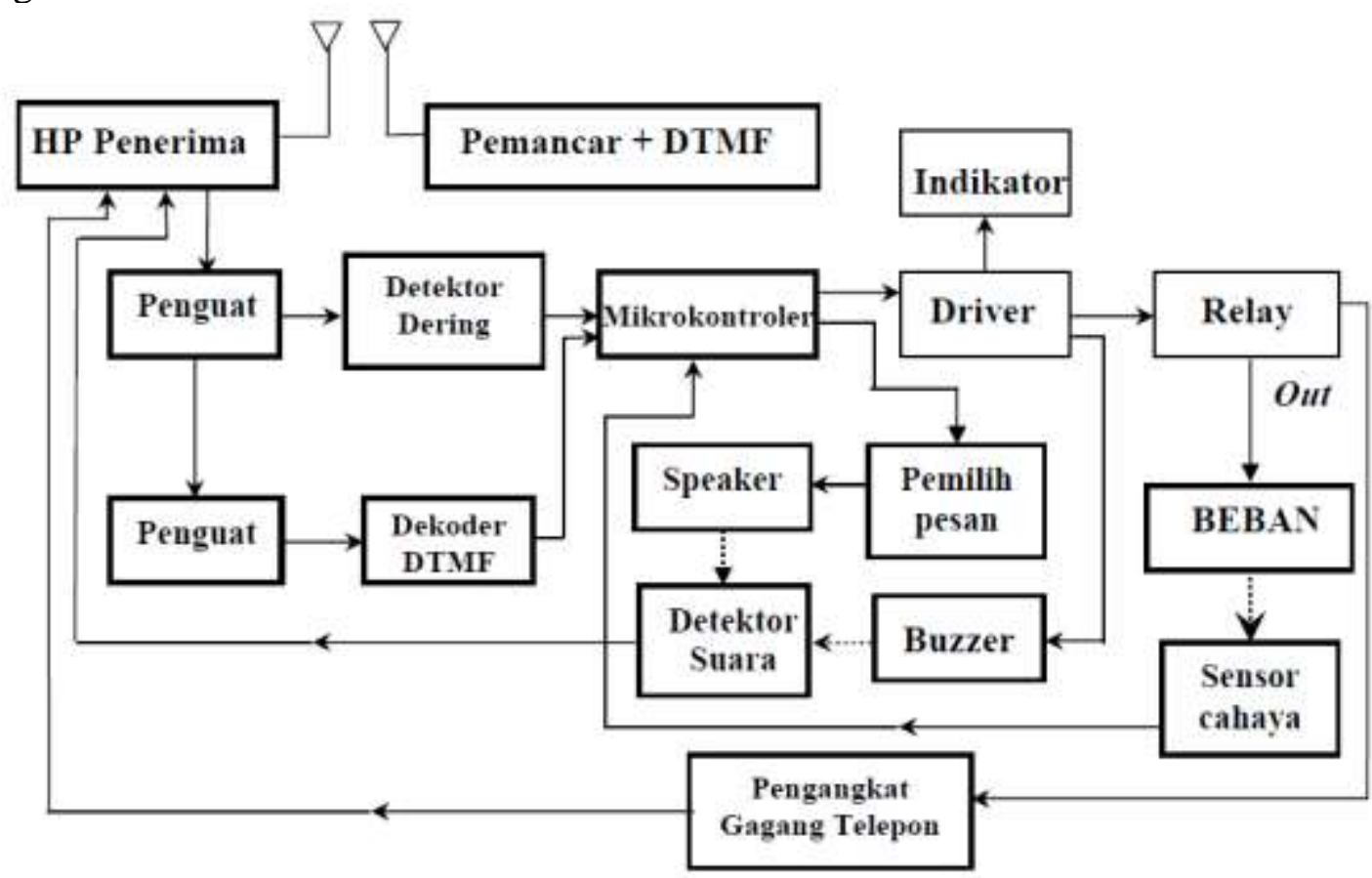

Gambar 3.1 Diagram Blok Perangkat Keras Kendali Perangkat Elektronik Via Telepon Selular Berbasis Mikrokontroler AT89C51

Dari diagram blok di atas dapat diterangkan prinsip dan cara kerjanya sebagai berikut : Kendali perangkat elektronik via telepon selular berbasis mikrokontroler AT89C51, memanfaatkan sinyal-sinyal DTMF yang dihasilkan oleh penekanan tombol-tombol keypad pada telepon selular yang kemudian didekodekan oleh IC MT8870 dan keluarannya dibandingkan dengan data yang telah tersimpan dalam mikrokontroler untuk melakukan proses selanjutnya. Sedangkan proses yang terjadi dalam mikrokontroler atau bisa juga disebut diagram alir atau flow chart-nya ditunjukkan dalam gambar 3.2. 
Jurnal Qua Teknika, Vol.6 No.2 September 2016

p ISSN: 2088 2424; e-ISSN: 2527 3892

UNISBA Blitar, Http://qua.unisbablitar.ejournal.web.id

Budi Artono, 2016. Telepon Selular Sebagai Pengendali Perangkat Elektronik Berbasis Mikrokontrol AT 89C51. Jurnal Qua Teknika, (2016), 6(2): 29 45

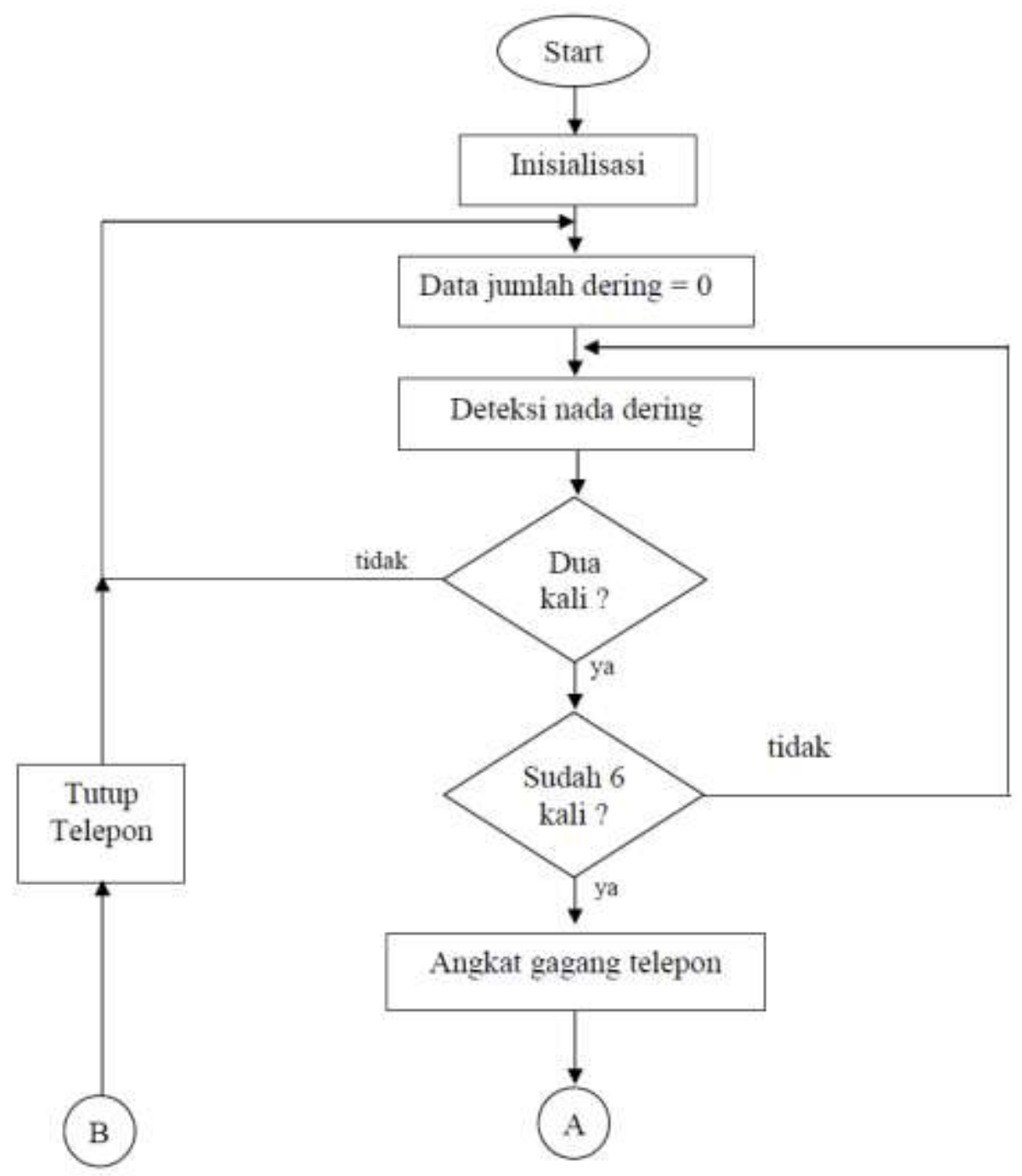




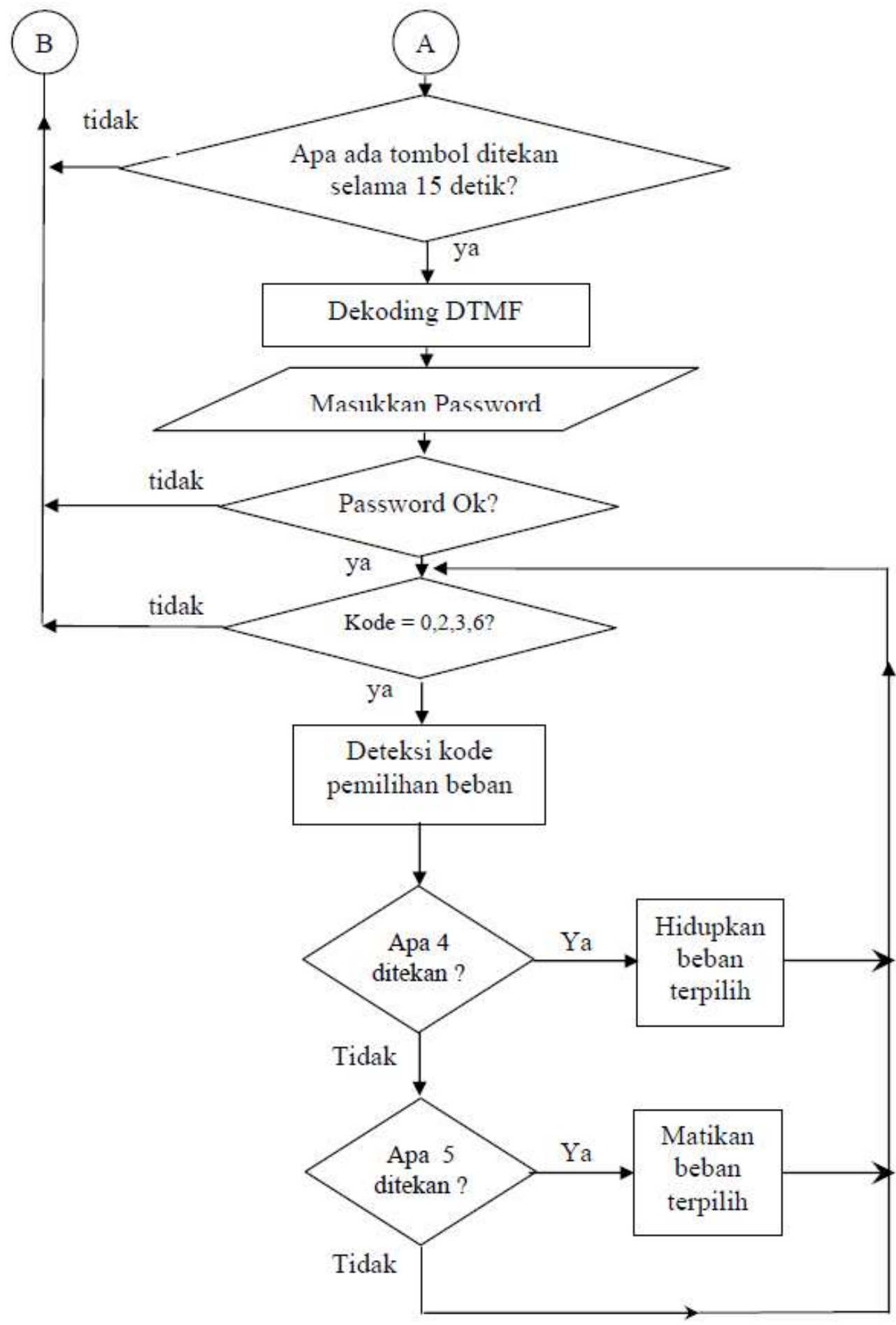

Gambar 3.2 Diagram Alir Kendali Perangkat Elektronik Via Telepon Selular Berbasis Mikrokontroler AT89C51 
Untuk bagian-bagian dalam blok diagram dari peangkat keras di atas dijelaskan pada item-item di bawah ini.

\subsection{Pemancar dan Penerima}

Untuk bagian pemancar dapat digunakan bermacam macam pesawat telepon baik pesawat telepon tetap maupun telepon mobile. Sedangkan pada bagian penerima digunakan telepon selular NOKIA 3350. Sebagai penghubung antara bagian penerima dan alat pengendali digunakan Hands Free NOKIA 3350 seperti ditunjukkan dalam gambar 3.3.
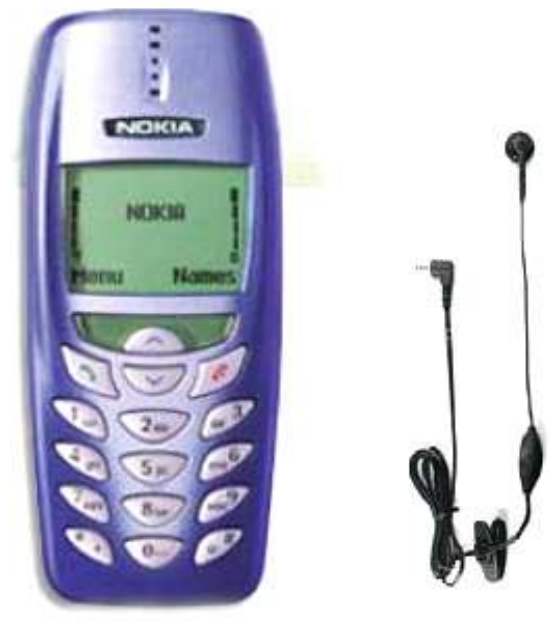

\section{Gambar 3.3 NOKIA 3350 dan Hands Free NOKIA}

\subsection{Detektor Nada Dering}

Sinyal output dari speaker hands free masih terlalu lemah untuk dapat mengaktifkan rangkaian detektor nada dering, sehingga diperlukan sebuah penguat dengan output sefase dengan sinyal inputnya. Maka disini digunakan operasional amplifier yang dibangun menggunakan IC LM 741. Untuk skema rangkaian penguatnya dapat dilihat pada gambar 3.4 Gambar 3.4 Penguat Non Inverting

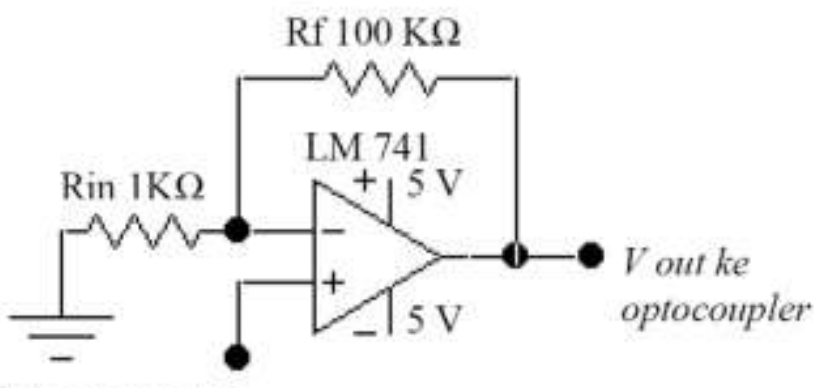

Output speaker

hands free

Gambar 3.4 Penguat Non Inverting

Rangkaian detektor nada dering yang dibangun dengan IC Opto Coupler 4N35 mempunyai fungsi yang sangat sederhana yaitu sebagai saklar, untuk menghubungkan kaki 
INT0(P3.2) atau pin 12 mikrokontroler dengan ground (0 Volt). Sinyal dering akan mengakibatkan denyut arus pada LED dalam optocoupler dengan frekuensi 20 sampai 40 Hertz, pada gilirannya mengakibatkan opto transistor dalam IC 4N35 on / off sesuai dengan arus yang mengalir pada LED tersebut. Kolektor dari optocoupler didalam IC 4N35 dihubungkan ke kaki INT0 (kaki nomor 12 AT89C51), pada kolektor ini tidak diperlukan lagi resistor yang dihubungkan ke Vcc mengingat tahanan semacam itu sudah ada di dalam chip AT89C51. Keadaan on / off dari opto transistor akan mengakibatkan kaki INT0 menjadi ' 0 ' / ' 1 ', saat tidak ada nada dering INT0 dalam keadaan ' 1 ' dan saat ada dering berbunyi selama 1 detik kaki INT0 akan berubah ' 0 ' / ' 1 ' sebanyak 10 sampai 20 pulsa tergantung pada frekuensi nada dering yang berkisar antara 20 sampai $40 \mathrm{Hertz}$. Sinyal pada kaki INT0 ini diterima AT89C51 sebagai sinyal permintaan layanan interupsi, tapi mengingat satu nada dering bisa terdiri dari 10 sampai 20 pulsa maka hanya perubahan ' 1 ', ke '0' yang pertama saja boleh dianggap sebagai sinyal interupsi.

Dari segi teknik pemrograman, hal ini bisa diselesaikan dengan cara sebagai berikut:

1. Dalam keadaan menunggu panggilan telepon, sarana interupsi INT0 diaktifkan.

2. Saat rutin layanan interupsi INT0 (ISR - Interrupt Service Routine) sarana interupsi INT0 di non aktifkan, dengan demikian setelah permintaan interupsi dilayani, pulsapulsa berikutnya pada dering bersangkutan tidak akan ditanggapi AT89C51 sebagai permintaan interupsi

3. Saat rutin layanan interupsi INT0 diatas, diaktifkan sistem timer dengan periode 4 detik, yakni satu periode waktu dimana dering pertama sudah selesai dan dering kedua tepat terjadi.

4. Lewat dari waktu 4 detik tersebut, sarana interupsi INT0 diaktifkan kembali agar AT89C51 bisa melayani dan menghitung nada dering berikutnya.

Selain dari hal tersebut di atas, masih diperlukan lagi sebuah timer lain. Timer yang satu ini periodenya sekitar 8 detik, yakni waktu yang diperlukan untuk mendeteksi nada dering berikutnya. Jika dalam periode waktu itu tidak ada nada dering yang diterima lagi, maka alat akan menganggap nada dering tadi 'miss call' sehingga program akan kembali menunggu nada dering selanjutnya dari awal.

Untuk skema rangkaian detektor nada dering dapat dilihat pada gambar 3.5

R2 $100 \mathrm{~K}$

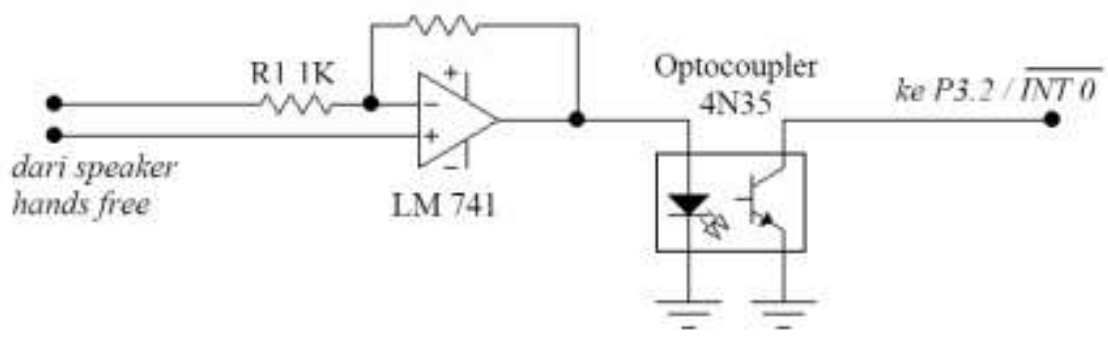

Gambar 3.5 Rangkaian Penguat dan Detektor Nada Dering

\subsection{Pengangkat Gagang Telepon}

Pengangkatan gagang telepon pada telepon selular pada dasarnya hanya menghubung singkat jalur pengangkat gagang telepon pada hands free dengan ground agar 
telepon selular siap berkomunikasi. Hal ini dapat disimulasikan dengan menggunakan relay. Skema rangkaian pengangkat gagang telepon dapat dilihat pada gambar 3.6

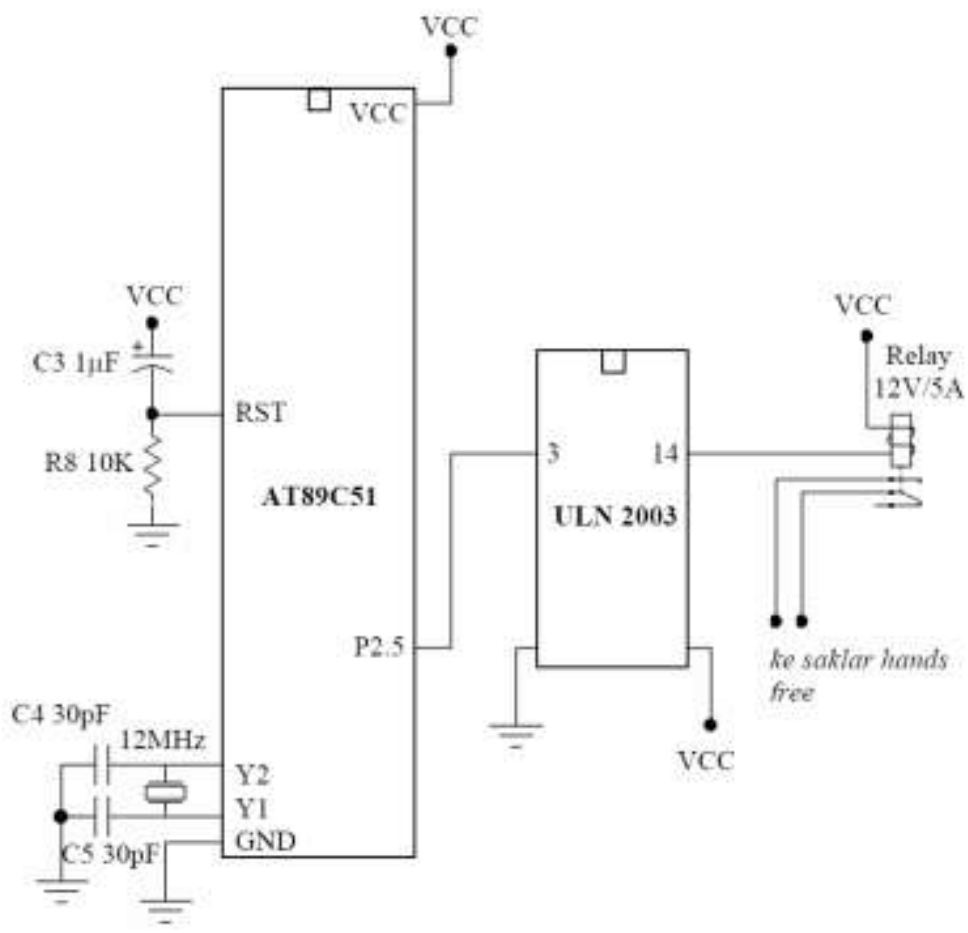

Gambar 3.6 Rangkaian Pengangkat Gagang Telepon

\subsection{Dekoder DTMF}

Untuk mengkodekan DTMF, dipakai IC MT8870 yang memang dirancang khusus untuk keperluan tersebut. Setiap kali MT8870 menerima nada DTMF, kaki StD (kaki 15 MT8870) akan menjadi '1', keadaan kaki ini dipantau AT89C51 lewat port P1.4 (kaki 5 AT89C51). Kode angka DTMF yang diterima MT8870 diterima AT89C51 lewat kaki P1.0 sampai P1.3 (kaki 1 sampai 4 AT89C51).

Dengan demikian pemantauan nada DTMF bisa dilakukan dengan menunggu P1.4 menjadi ' 1 ', jika tidak ada nada DTMF yang diterima, maka dipantau pula apakah selang waktu 15 detik sudah lewat, jika sudah lewat maka secara otomatis alat akan memutuskan komunikasi dan siap memantau nada dering selanjutnya. Kode akses yang diperlukan untuk manggerakkan beban merupakan kode biner 4 bit yang diterima dari MT8870. Kode ini dibandingkan dengan kode yang sudah ditentukan di dalam program, jika ternyata sesuai maka proses berikutnya diteruskan, jika tidak gagang telepon diletakkan kembali dan proses selesai. Berikutnya alat ini sudah siap menerima perintah-perintah untuk menggerakkan beban. Perintah-perintah untuk menggerakkan beban satu persatu diakhiri dengan kombinasi tombol 4 (empat) atau 5 (lima).

Untuk skema rangkaian pemantau nada DTMF dapat dilihat pada gambar 3.7 


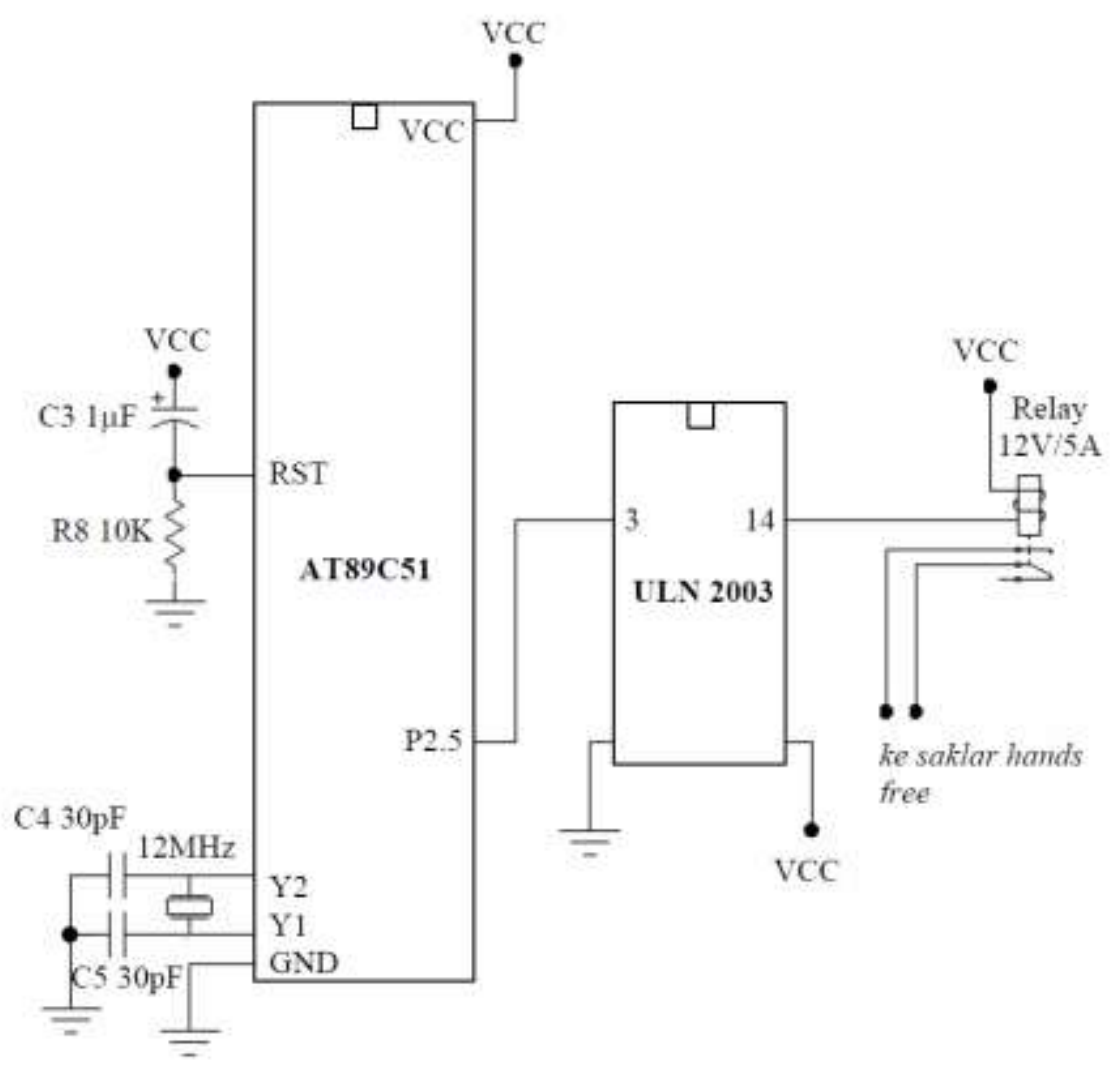

Gambar 3.7 Rangkaian Dekoder DTMF

\subsection{Driver}

Rangkaian ini berfungsi sebagai perantara dari bagian control utama yang menghasilkan tegangan berlogika tinggi atau logika rendah dengan saluran beban AC sebagai perangkat luar yang akan dikendalikan, sehingga dapat diartikan pada bagian ini berupa kontak yang mengkoneksikan atau mengendalikan beban AC yang terkendali dari sinyal digital. Sebagai komponen utamanya, bagian ini terdiri dari komponen IC ULN 2003 yang dioperasikan sebagai saklar elektronis dan komponen relay sebagai kontaknya. Logika keluaran dari rangkaian control utama yang bernilai tinggi (5 volt) menyebabkan keluaran dari IC ini berlogika rendah dan logika rendah ini dapat menggerakan relay yang berfungsi sebagai kontaknya untuk menghidupkan beban. Jika logika dari rangkaian control utama rendah (0 Volt) maka output ULN 2003 berlogika tinggi sehingga kontak terputus dan beban AC mati. Skema rangkaian switching dapat dilihat pada gambar 3.8 


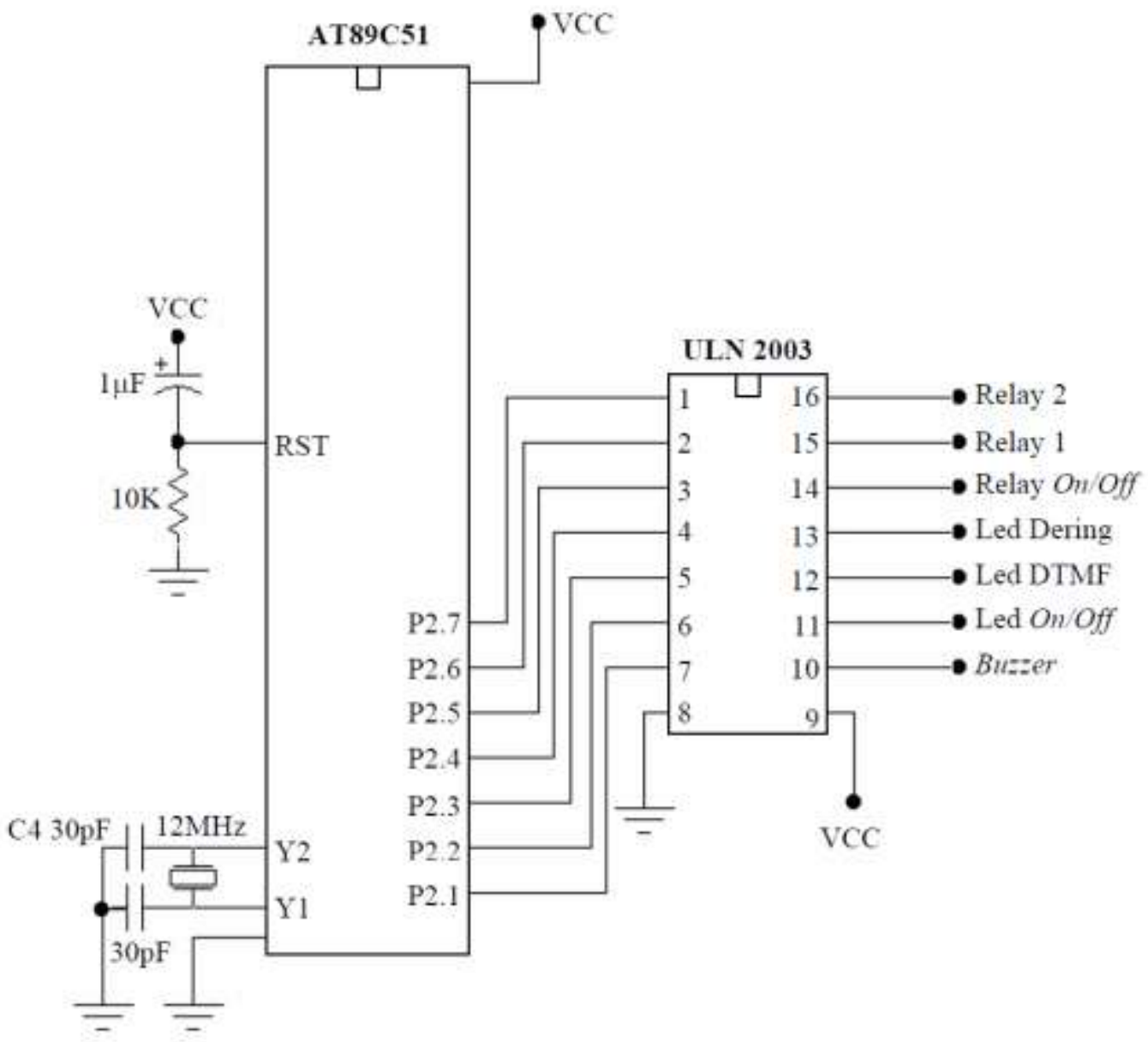

Gambar 3.8 Skema Rangkaian Driver

\subsection{Detektor Beban, Indikator dan Pemilih Pesan Suara}

Rangkaian detektor berfungsi sebagai pendeteksi keadaan beban, apakah sudah berhasil dikendalikan atau belum. Detektor beban ini berupa untai sensor cahaya, dengan komponen utama LDR (Ligt dependent resistor) karena beban yang dikendalikan adalah lampu. Keadaan beban akan dimonitor oleh untai sensor cahaya ini. Hasil dari untai sensor digunakan untuk umpan balik ke mikrokontroler yaitu pada port P0.1 dan P0.2. Perubahan keadaan pada port P0.1 dan P0.2 inilah yang kita gunakan untuk mengendalikan untai pemilih pesan suara yang dibangun dengan komponen utama IC chipcorder ISD2590 yang kita set pada operation mode. Rangkaian detektor beban ditunjukkan pada gambar 3.9. 


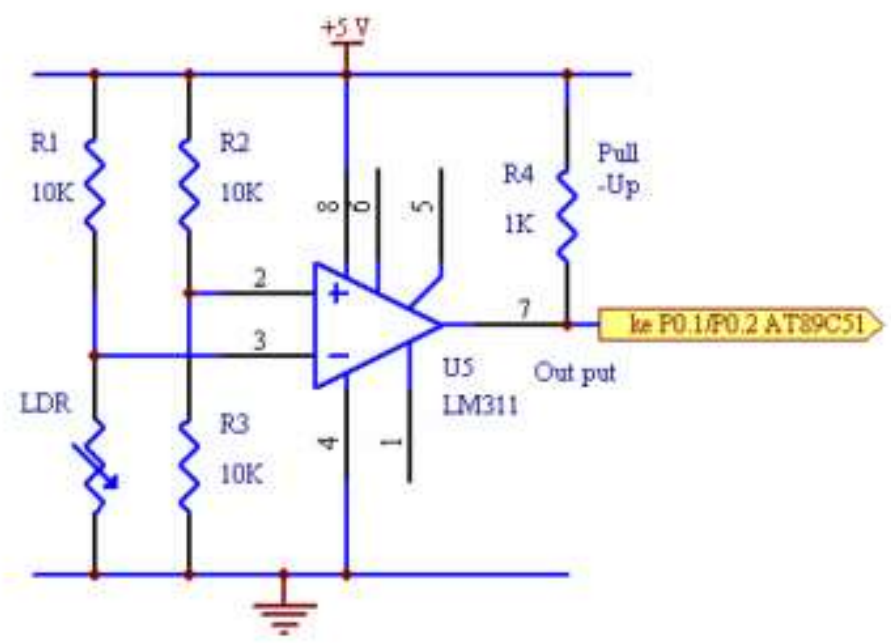

Gambar 3.9 Rangkaian Detektor Beban

Selain detektor, pada perangkat yang dibuat juga dipasang indikator yang berupa LED. Rangkaian indikator ditunjukkan pada gambar 3.10. 62

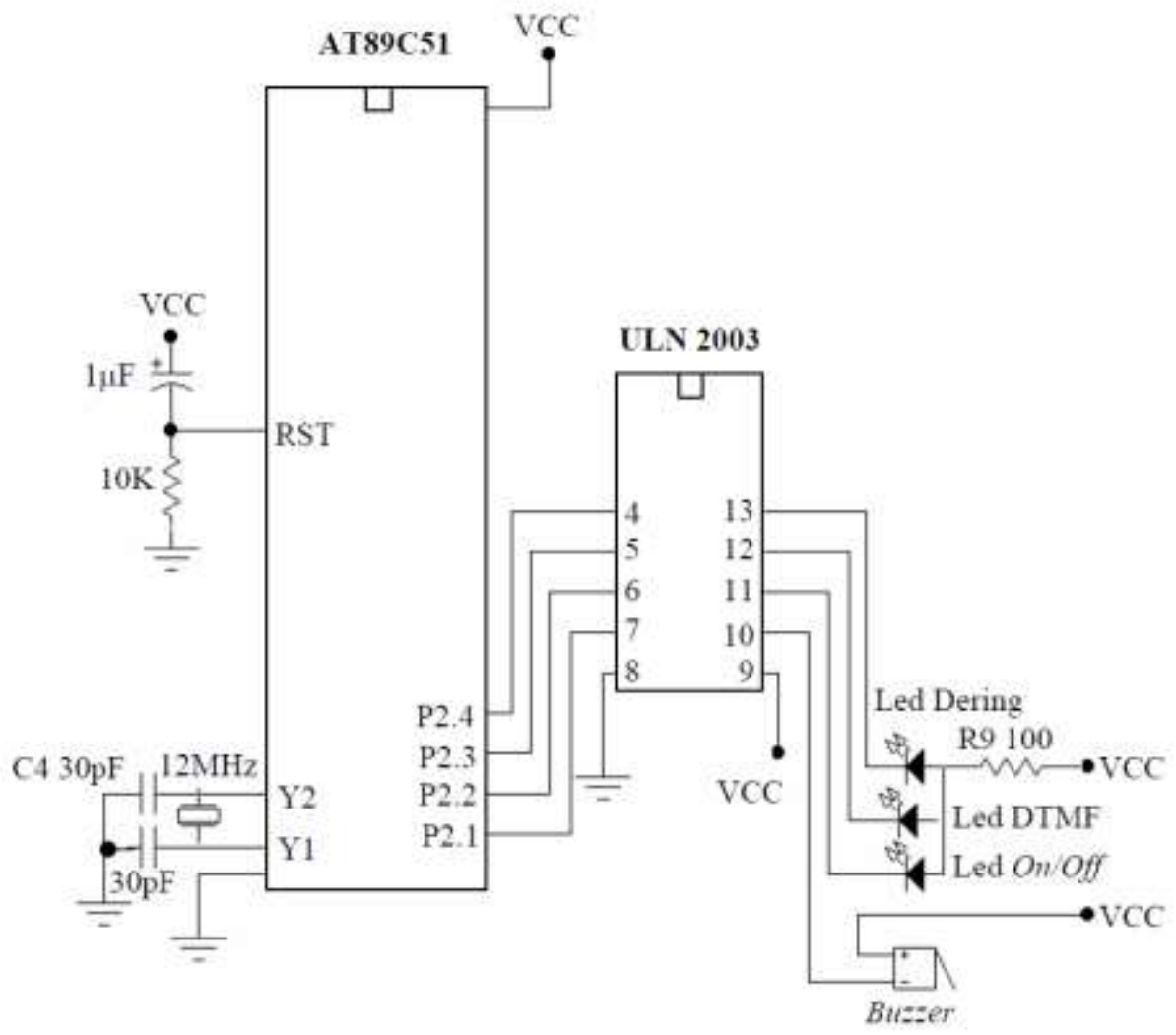

Gambar 3.10 Rangkaian Indikator

Kemudian untuk rangkaian pemilih pesan suara ditunjukkan pada gambar 3.11. Pemilih pesan suara ini dibangun dengan komponen utama IC chipcorder ISD2590 yang berfungsi untuk memilih pesan yang berupa suara yang terekam di dalam IC tersebut. Di dalam IC bisa kita simpan beberapa pesan, kemudian dengan mengoperasikan ISD2590 pada 
operation mode kita bisa memanggil pesan suara sesuai dengan data yang diperoleh dari sensor.

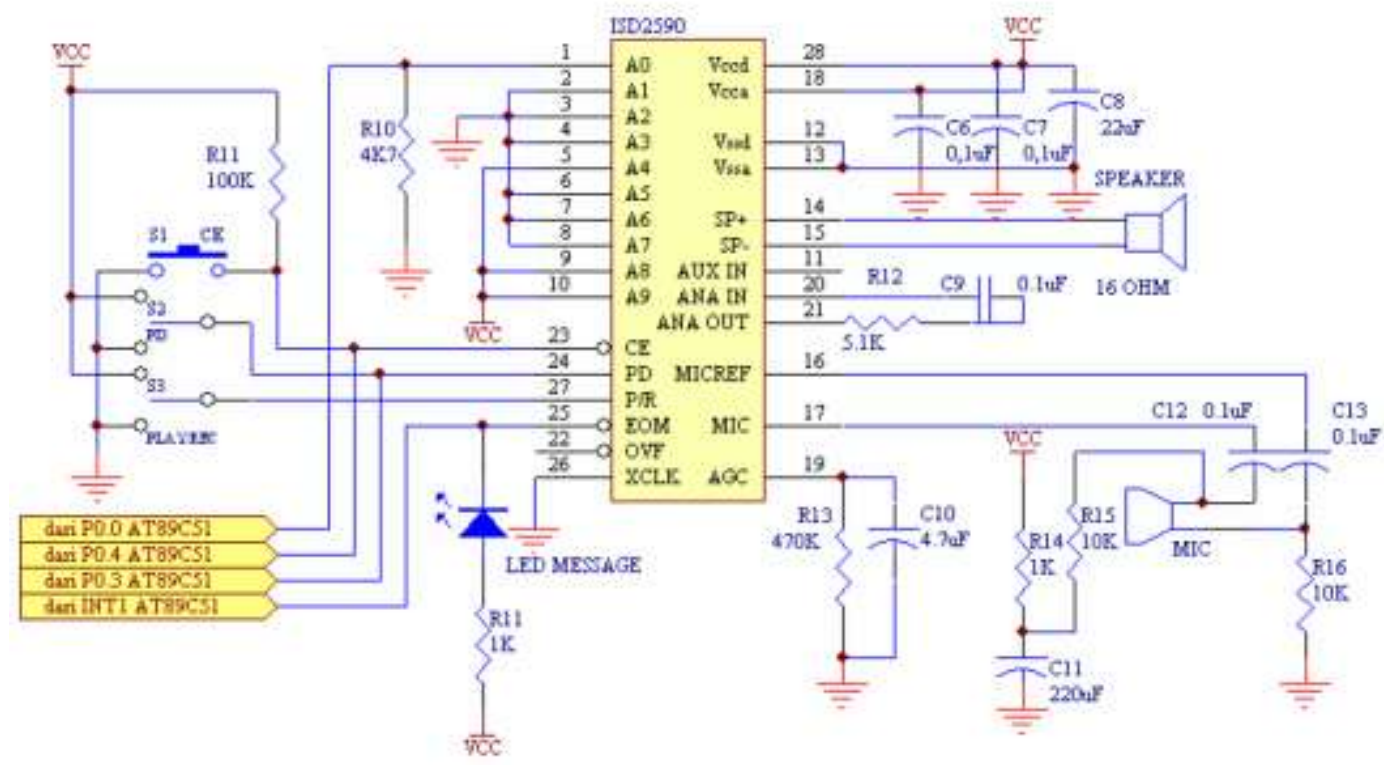

Gambar 3.11 Rangkaian Pemilih Pesan Suara

Keluaran ISD2590 yang berupa suara disesuaikan dengan hasil pengendalian beban dengan tiga kaki kendali yaitu kaki CE, PD dan EOM, pengendalian tiga kaki tersebut juga dilakukan oleh mikrokontroler. Kemudian keluaran ISD2590 yang berupa suara dikirimkan kembali ke pengirim kendali dengan mikropon pada hans free HP penerima. Di akhir pesan ditutup dengan bunyi beep dari buzzer.

\subsection{Catu Daya}

Catu daya dalam sebuah rangkaian sangatlah vital peranannya, untuk itu diperlukan kestabilan yang mantap dan grounding yang baik. Catu daya berfungsi menyediakan tegangan ke masing-masing blok rangkaian agar dapat bekerja dengan baik. Tegangan yang diperlukan pada rangkaian pengendali ini adalah 12 Volt untuk IC ULN 2003, Buzzer dan Relay. Tegangan 5 Volt untuk IC AT89C51, IC MT8870 dan IC LM 741. Disini juga diperlukan tegangan -5 Volt untuk IC LM 741 karena memerlukan catu simetris. Untuk catu daya mikrokontroler AT89C51 menggunakan trafo 1 A tersendiri untuk menjaga kestabilan arus agar mikrokontroler tidak hang karena kekurangan arus. Untuk skema rangkaiannya dapat dilihat pada gambar 3.10 

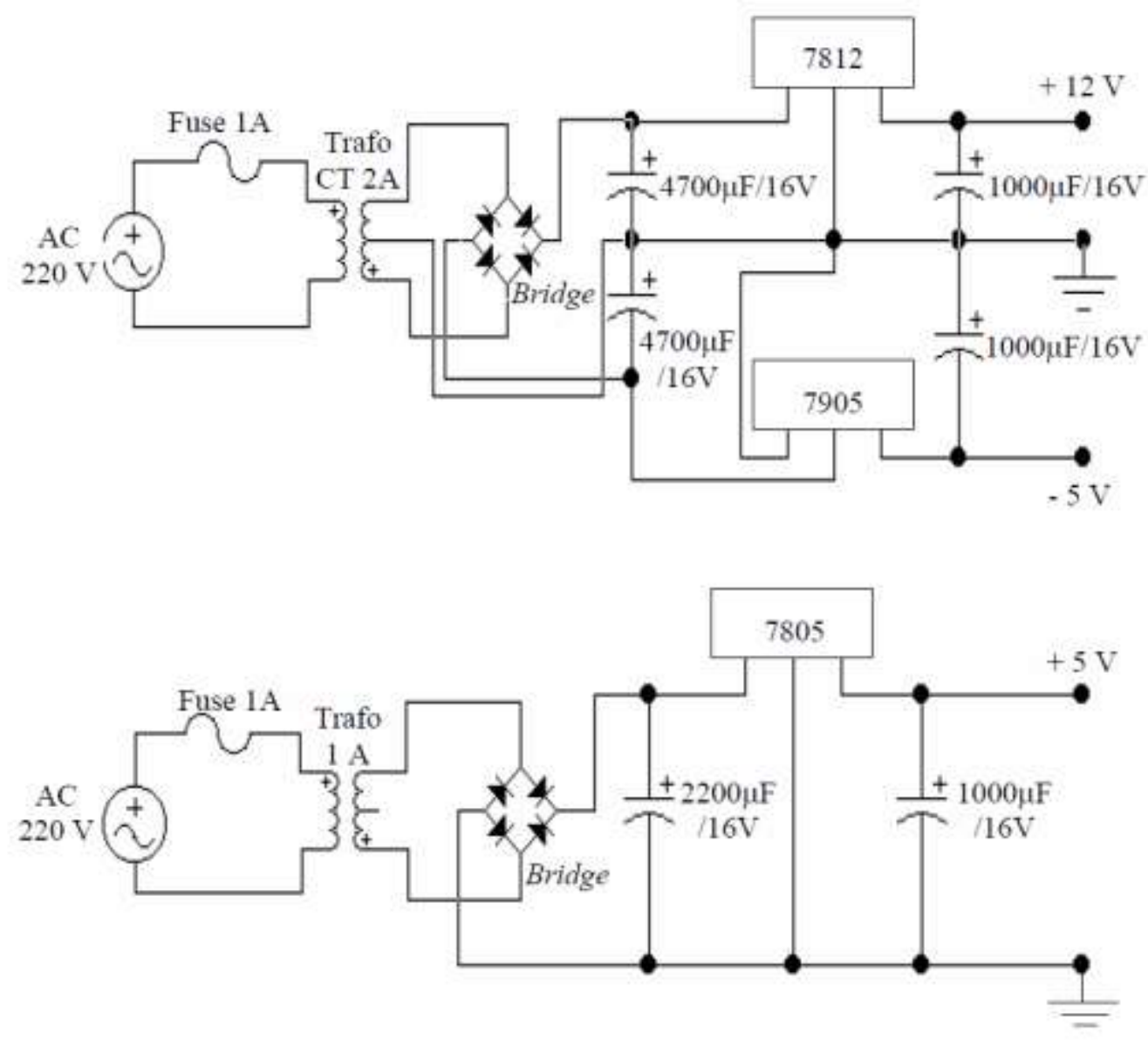

\subsection{Software}

Gambar 3.12 Rangkaian Catu Daya

Mikrokontroler adalah sistem dalam bentuk chip yang disusun secara minimal dan digunakan sebagai pengendali sesuai dengan program yang masuk kedalamnya. Program adalah perangkat lunak yang terdiri atas sekumpulan intruksi atau perintah yang tersusun secara teratur dan dapat dieksekusi, sehingga dapat mengaktifkan sistem mikrokontroler. Bahasa pemrograman yang dipakai penulis dalam perancangan perangkat lunak ini menggunakan bahasa assembly. Kapasitas program yang dihasilkan dari bahasa pemrograman assembly relatip lebih sedikit dari bahasa pemrograman lainnya. Alat kendali jarak jauh ini memerlukan perangkat lunak di mikrokontrolernya yang digunakan untuk mengatur kerja perangkat keras dan melakukan operasi aritmatika. Bahasa assembly mempunyai beberapa kelebihan dibandingkan bahasa pemrograman lainnya. Selain kecepatan program yang dihasikannya lebih baik, kelebihan lain dari bahasa assembly adalah:

a. Memiliki fasilitas fungsi dan makro (sebuah ciri khas bahasa pemrograman tingkat tinggi yang menyebabkan pemrograman menjadi lebih baik).

b. Pemrograman dapat dibuat secara modular (dipecah dalam modul-modul kecil dan kemudian diintegrasi kembali).

c. Ukuran program lebih kecil, sehingga lebih menghemat media penyimpanan dalam mikrokontroler.

d. Lebih dekat ke hardware sehingga seluruh kemampuan komputer dapat dimanfaatkan secara maksimal. 
Untuk informasi yang dikirimkan ke pengirim kendali disesuaikan dengan hasil pengendalian yang terjadi pada beban. Untuk diagram alirnya ditunjukkan pada gambar 3.13 .

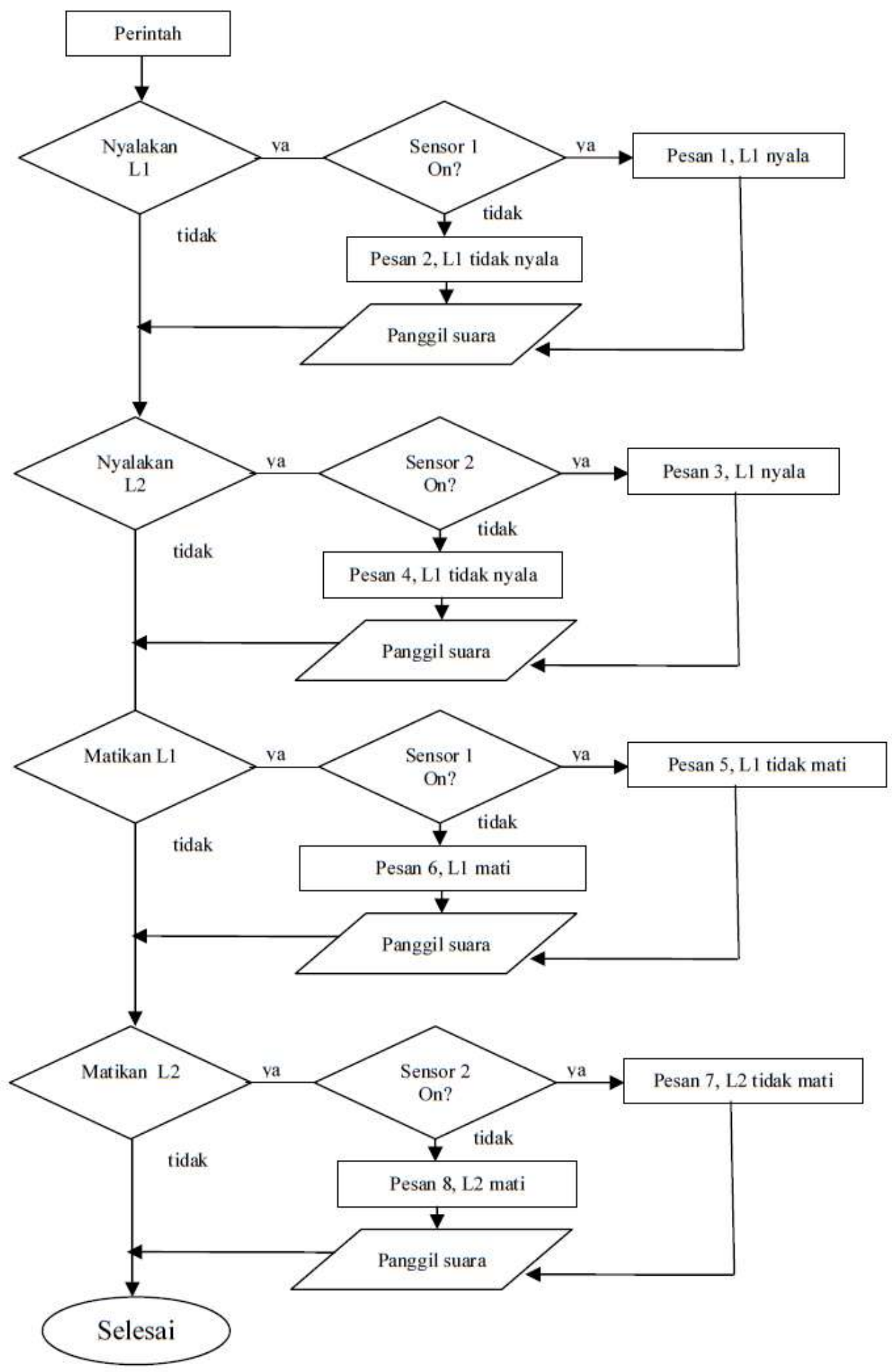

Gambar 3.13 Diagram alir untuk informasi keadaanbeban untuk pengirim kendali 


\subsubsection{Mengkompilasi Program}

Mengkompilasi program ASM51 tidak jauh beda dengan mengkompilasi bahasa-bahasa pemrograman lainnya. Media yang digunakan untuk menulis program ASM51 tidak harus media itu sendiri, tapi dapat dibuat dengan media editor, word star, note pad, dan lain sebagaianya. Program yang berekstensi ASM dikompilasi dengan file ASM51.EXE.

Setelah diaplikasikan program memiliki tiga file, dan diantaraya lst dan obj. File berekstensi $l s t$ dapat digunakan untuk memeriksa kesalahan program pada saat dikompilasi. Sedangkan file berekstensi obj digunakan untuk file objek yang akan diubah menjadi file berekstensi HEX.

\section{PENGUJIAN DAN ANALISIS}

\subsection{Pengujian Sistem}

Dalam melakukan pengujian rangkaian, bisa dilakukan dengan menggunakan peralatan multimeter dan LED (Light Emitting Diode). Pengujian rangkaian dilaksanakan dalam setiap blok dari rangkaian keseluruhan. Hal ini untuk mempermudah dalam memeriksa tingkat kesalahan dari rangkaian yang telah dibuat.

Bagian-bagian yang akan diuji antara lain:

1. Blok rangkaian detektor nada dering

2. Blok rangkaian dekoder DTMF

3. Blok rangkaian mikrokontroler

4. Blok rangkaian driver

\subsubsection{Pengujian Rangkaian Detektor Nada Dering}

Pengujian rangkaian detektor nada dering dilakukan dengan cara sebagai berikut:

1. Menghubungkan rangkaian dengan catu daya.

2. Menghubungi nomor telepon yang dipararel dengan rangkaian.

3. Mengukur tegangan keluaran dari kaki optocoupler 4N35. Hasil pengukuran dapat dilihat pada tabel 4.1.

4. Menghubungkan katoda LED yang sudah terhubung dengan +5 Volt,dengan kaki nomor 5 optocoupler. Hasil pengamatan dapat dilihat pada tabel 4.2.

Tabel 4.1 Pengujian rangkaian detektor dering

\begin{tabular}{|c|c|c|}
\hline Kondisi Hp Penerima & Tegangan Keluaran IC 4N35 & Logika Keluaran \\
\hline Ada nada dering & 2,4 Volt & $' 0 '$ \\
\hline Tidak ada nada dering & 4,9 Volt & $' 1$ ' \\
\hline
\end{tabular}

Tabel 4.2 Pengamatan rangkaian detektor dering

\begin{tabular}{|c|c|c|}
\hline Kondisi Hp Penerima & Keadaan LED & Logika Keluaran \\
\hline Ada nada dering & Hidup & ' 0 \\
\hline Tidak ada nada dering & Mati & ' 1 ' \\
\hline
\end{tabular}

\subsubsection{Pengujian Rangkaian Dekoder DTMF}

Pengujian nada DTMF receiver bertujuan untuk mengetahui bahwa rangkaian yang telah dibuat dapat berfungsi mendekodekan atau mengubah sinyal DTMF dari telepon penerima menjadi data biner 4 bit. Cara melakukan pengujian rangkaian ini adalah dengan menghubungkan rangkaian ini dengan hands free yang terkoneksi dengan telepon penerima, setelah itu rangkaian diberi tegangan 5 Volt. Pada saat tombol key pad ditekan maka keluaran dari StD (Delayed 81 Steering) akan high (3,2 Volt) dan D0 (pin 11) sampai dengan 
D3 (pin 14) akan menghasilkan data sesuai dengan karakter tombol yang ditekan dalam bentuk kode BCD (Binery Code Decimal).

Keluaran rangkaian DTMF receiver yaitu D0, D1, D2 dan D3 dihubungkan dengan 4 buah LED agar data keluaran dapat dilihat. Keluaran logika '1' dari rangkaian ini ditandai dengan menyalanya lampu LED dan pada saat diukur tegangannya, keluarannya sebesar 5 Volt. Sedangkan pada saat logika '0', LED tidak menyala dan tegangan keluaran adalah 0 Volt. Hasil pengujian DTMF receiver ditunjukan pada tabel 4.3.

Tabel 4.3 Hasil Pengujian DTMF Receiver

\begin{tabular}{|c|c|c|c|c|}
\hline Tombol & D3 & D2 & D1 & D0 \\
\hline 1 & 0 & 0 & 0 & 1 \\
\hline 2 & 0 & 0 & 1 & 0 \\
\hline 3 & 0 & 0 & 1 & 1 \\
\hline 4 & 0 & 1 & 0 & 0 \\
\hline 5 & 0 & 1 & 0 & 1 \\
\hline 6 & 0 & 1 & 1 & 0 \\
\hline 7 & 0 & 1 & 1 & 1 \\
\hline 8 & 1 & 0 & 0 & 0 \\
\hline 9 & 1 & 0 & 0 & 1 \\
\hline 0 & 1 & 0 & 1 & 0 \\
\hline$\#$ & 1 & 0 & 1 & 1 \\
\hline$*$ & 1 & 1 & 0 & 0 \\
\hline
\end{tabular}

\subsubsection{Pengujian Rangkaian Mikrokontroler}

Rangkaian Mikrokontroler dapat diuji dengan cara sebagai berikut:

1. Pada mikrokontroler, program awal untuk Port yang menuju ke beban dan ke indikator LED akan reset terlebih dahulu pada saat diberi tegangan 5 Volt. Hal ini akan menyebabkan relay akan on / off dengan cepat, ini bisa dijadikan indikator bahwa mikrokontroler dalam keadaan baik.

2. Memberikan sinyal dering (logika '0') pada Port P3.2 sebanyak enam kali, setiap 1 kali sinyal dering Port P2.4 akan berlogika ' 1 ' (2,2 Volt). Setelah enam kali maka pada Port P2.2 dan Port P2.5 akan berlogika ' 1' (1,6 Volt) kurang lebih 0,5 detik.

\subsubsection{Pengujian Rangkaian Driver}

Rangkaian Driver dapat diuji dengan cara sebagai berikut:

1. Menghubungkan rangkaian dengan catu daya 12 Volt.

2. Memberikan tegangan masukan pada kaki input ULN 2003 dan mengukur outputnya

3. Memperhatikan pergerakan relay dan indikator-indikator lainnya.

Hasil dari pengukuran dan pengamatan ini menunjukkan bahwa jika masukan dari rangkaian ini berlogika ' 1 ' (1,6- 2,2 Volt), maka tegangan keluaran darai ULN 2003 adalah berlogika ' 0 ' $(0,8$ Volt $)$ sehingga relay dan indikator-indikator lainnya akan aktif. Sedangkan bila masukan berlogika '0' maka tegangan output dari ULN 2003 mendekati tegangan VCC (12 Volt) sehingga relay dan indikator-indikator lainnya akan tidak aktif. Hal ini menunjukan bahwa rangkaian telah bekerja dengan baik. Hasil dari pengujian rangkaian driver dapat dilihat pada tabel 4.4.

Tabel 4.4 Pengujian Rangkaian Driver

\begin{tabular}{|c|c|}
\hline Masukan ULN & Tegangan keluaran ULN \\
\hline Logika '1' & 0,8 Volt \\
\hline
\end{tabular}




\begin{tabular}{|c|c|}
\hline Logika '0' & 13 Volt \\
\hline
\end{tabular}

\subsection{Analisis Sistem}

Sistem pengendalian perangkat elektronik dari jarak jauh menggunakan telepon selular dapat dilakukan dengan baik walaupun masih terbentur pada masalah jaringan operator telepon selular. Untuk mengoperasikannya alat ini dapat dilakukan dengan menghubungi nomor telepon pada pesawat penerima yang terpasang dengan alat ini. Dari hasil pengujian sistem maka dapat dianalisis rangkaian-rangkaian sistem tesebut sebagai berikut:

\subsubsection{Analisis Rangkaian Detektor Nada Dering}

Rangkaian Detektor Nada Dering yang dibangun menggunakan IC 4N35, merupakan sebuah interface antar muka antara bagian penerima dengan Mikrokontroler AT89C51. Rangkaian ini berfungsi sebagai detektor adanya dering telepon dari bagian penerima. Bila terjadi dering telepon maka output rangkaian ini dapat dimanfaatkan sebagai pengaktif INT0 pada Mikrokontroler AT89C51.

\subsubsection{Analisis Rangkaian Dekoder DTMF}

Rangkaian decoder DTMF yang dibangun dengan komponen utamanya IC MT8870 berfungsi untuk mengkodekan nada akibat dari penekanan tombol key pad yang sesuai dengan frekuensi standar DTMF yang kemudian didekodekan menjadi kode biner 4 bit. Dan hasil pengkodean dari hasil penekanan tombol-tombol key pad pada telepon selular disajikan pada tabel 4.3 .

\subsubsection{Analisis Rangkaian Mikrokontroler}

Rangkaian Mikrokontroler merupakan rangkaian paling utama dari rangkaian kendali perangkat elektronik via telepon selular berbasis mikrokontroler AT89C51. Rangkaian ini merupakan otak dari device driver, yang dapat mengendalikan beberapa beban output sesuai dengan input masukan. Mikrokontroler akan membandingkan data-data input dengan program yang telah dimasukkan dalam Flash PEROMnya untuk melakukan proses pengendalian.

\subsubsection{Analisis Rangkaian Driver}

Rangkaian Driver dengan komponen utamanya IC ULN 2003 berfungsi mengaktifkan relay atau indikator-indikator lainnya dengan memberikan logika ' 1 ' pada input ULN 2003. Rangkaian ini digunakan karena keluaran dari mikrokontroler tidak dapat langsung digunakan untuk mengerakkan relay, karena arus keluaran mikrokontroler sangat kecil. IC ULN 2003 dapat diandalkan sebagai komponen rangkaian driver karena konstruksinya menggunakan transistor darlington dan sudah dilengkapi pula dengan diode penyearah untuk melindungi rangkaian driver itu sendiri.

\subsubsection{Analisis Rangkaian Detektor Beban dan Pemilih Pesan Suara}

Pemilih pesan suara bekerja sesuai dengan informasi yang diberikan detektor beban ke mikrokontroler, yaitu untuk detektor beban 1 ke port P0.1 dan keluaran detektor beban 2 ke port P0.2 AT89C51. Kemudian prubahan yang terjadi pada port P0.1 dan P0.2 tersebut kita gunakan untuk mengontrol ISD2590 dengan bantuan kontrol mikrokontroler pin P0.3 dan P0.4 dan INT1. Keberhasilan informasi yang dikirmkan kembali ke pengirim kendali tergantung bagus tidaknya rangkaian detektor beban dan stabilitas kerja dari ISD2590.

\section{KESIMPULAN}


Setelah menyelesaikan penelitian ini dan merealisasikannya dalam bentuk alat yang sesungguhnya, serta melakukan pengujian sistem maka penulis dapat menarik beberapa kesimpulan yang dapat dijadikan catatan dalam pengembangan selanjutnya. 1) Nada DTMF pada telepon selular dapat dimanfaatkan untuk pengendalian perangkat elektronik dengan dukungan kemampuan mikrokontroler AT89C51. 2) Kendali perangkat elektronik via telepon selular sudah dapat diwujudkan guna mengatasi kendala pengendalian suatu sistem yang masih dibatasi dimensi jarak, ruang dan waktu. 3) Efisiensi akan tercapai dengan penggunaan Mikrokontroler AT89C51 sebagai kontrol utama karena mempunyai 32 unit input / output serta harga IC yang relatif murah dan mudah diperoleh dipasaran, dan dapat diwujudkan dalam rangkaian yang lebih sederhana daripada menggunakan IC digital lainnya. 4) Kegagalan dalam pengendalian perangkat elektronik via telepon selular lebih banyak disebabkan karena masalah sinyal jaringan operator telepon selular.

\section{DAFTAR PUSTAKA}

Agfianto.E.P, 2002, Belajar Mikrokontroler AT89C51/52/55 Teori dan Aplikasi, Gava Media, Yogyakarta

Binatronika, 1984, Penerapan Aneka IC TTL-CMOS-LINIER, Binatronika, Bandung

Clive Braithwaite, Jeffrey Hall, Paul Fay, Roy Pickup, 1985, Pengantar Ilmu Teknik Elektronika, PT Gramedia, Jakarta

Kelompok Gramedia, 1994, Elektronika Eksperimen, PT Elex Media Komputindo

Moh. Ibnu Malik, 2003, Belajar Mikrokontroler PIC16F84, Gava Media, Yogyakarta

Paulus.A.N, 2003, Teknik Antarmuka dan Pemrograman Mikrokontroler AT89C51, PT Elex Media Komputindo, Jakarta

Www.alds.stts.edu/digital/DTMF_monitor.htm 